\title{
Efecto de la Administración de Ácido Retinoico Sobre el Desa- rrollo del Esqueleto Axial en Embriones de Ratón Mus musculus
}

\author{
Effect of Administration of Retinoic Acid on the Development \\ of the Axial Skeleton in Mouse Embryos Mus musculus
}

Gladys Ojeda Moris*; Yocelyn López Tardón*; Marcela Díaz Navarrete* \& Mariana Rojas Rauco*,****

OJEDA, M. G.; LOPEZ, T. Y.; DIAZ, N. M. \& ROJAS, R. M. Efecto de la administración de ácido retinoico sobre el desarrollo del esqueleto axial en embriones de ratón Mus musculus. Int. J. Morphol., 32(4):1449-1456, 2014.

RESUMEN: El déficit y exceso de vitamina A provoca malformaciones congénitas que afectan distintos órganos y sistemas. El objetivo de este estudio fue determinar el efecto que causa la administración de ácido retinoico a distintas dosis sobre la morfogénesis ósea del esqueleto axial en embriones de ratón Mus musculus. Mediante aleatorización simple se distribuyeron hembras recién preñadas en 4 categorías: A, B, C y D. El día 8 post fecundación (p.f), se administró $40 \mathrm{mg} / \mathrm{kg}$ de peso de ácido retinoico al grupo A, $20 \mathrm{mg} / \mathrm{kg}$ de peso de esta solución al grupo B, $1 \mathrm{ml} / \mathrm{kg}$ de peso de dimetil sulfóxido al grupo C, y el grupo D es grupo control. El día 17 de la gestación las hembras y sus fetos fueron anestesiadas y eutanasiadas con sobredosis de pentotal sódico intraperitoneal. Los fetos de cada camada fueron procesados mediante diafanización y tinción con azul de Alcian para destacar cartílago hialino y alizarina para observar tejido óseo. Los resultados se expresaron en porcentajes de malformaciones en los siguientes tres segmentos: 1) cráneo-columna cervical, 2) segmento torácico y abdominal y 3) cintura pélvica, considerándose un 100\% cuando la totalidad de los elementos óseos se encontraban comprometidos. Se utilizó la prueba de Fisher para la comparación de frecuencias de malformaciones y se consideró estadísticamente significativo cuando $\mathrm{p}<0,05$. En el grupo A se evidenciaron malformaciones mayores como ausencia de huesos frontales y parietales, exencefalia, defectos en el número de vértebras, y fusiones de costillas; y en el grupo B se observaron malformaciones menores como alteraciones numéricas y fusiones de costillas, existiendo diferencias significativas entre ambos grupos. En los grupos $\mathrm{C}$ y $\mathrm{D}$ no se consignaron malformaciones. El ácido retinoico administrado intraperitonealmente el dìa 8 p.f en dosis de 40 y $20 \mathrm{mg} / \mathrm{kg}$ de peso se comporta como un teratógeno en los embriones de ratón, existiendo además diferencias significativas entre las malformaciones generadas por ambas dosis de ácido retinoico. La primera concentración afecta los huesos de los tres segmentos estudiados (cráneo-cervical, toracoabdominal, y pélvico) y la segunda concentración sólo afecta a dos segmentos (cráneo-cervical y toracoabdominal). Ambos tratamientos afectan los segmentos en una gradiente céfalo caudal, independiente del origen embrionario de las estructuras. Esto se debería a que los cambios en las gradientes de ácido retinoico alteran el comportamiento de células de la cresta neural craneal y el orden de la expresión de genes Hox.

PALABRAS CLAVE: Ácido retinoico; Esqueleto axial; Malformaciones congénitas; Mus musculus; Feto; Ratón.

\section{INTRODUCCIÓN}

La OMS define malformación congénita como "toda anomalía del desarrollo morfológico, estructural, funcional o molecular como resultado de una embriogénesis defectuosa". El 10\% de las malformaciones congénitas se atribuyen a causas ambientales, el $25 \%$ a factores genéticos y el $65 \%$ a factores desconocidos probablemente de orden multifactorial (Rojas \& Walker, 2012).

Durante el desarrollo embrionario un grupo de células produce y secreta un morfógeno denominado ácido retinoico. Los morfógenos son moléculas de señalización secretadas en una región restringida del embrión (somitos) que difunden lejos de su fuente para formar una gradiente de concentración. Esta gradiente de señalización regula la expresión diferencial de genes de una manera dependiente de la concentración (Gurdon \& Bourillot, 2001; Tabata \& Takei, 2004; Rojas et al., 2014; Rojas \& Smok, 2014),

Por otra parte, la vitamina A está disponible en diversos vegetales. Sin embargo también se encuentra en productos de tratamiento cosmético, tratamiento para acné quístico severo, psoriasis (Brito et al., 2010; Crandall et al., 2004) y multivitamínicos. Tienen un rol esencial en la morfogénesis durante el período embrionario (Ross et al.,

* Departamento de Promoción de la Salud de la Mujer y el Recién Nacido, Facultad de Medicina, Universidad de Chile, Santiago, Chile.

** Laboratorio de Embriología Comparada, Facultad de Medicina, Universidad de Chile, Santiago, Chile.

**** Programa de Doctorado en Ciencias Morfológicas, Universidad de La Frontera, Chile. 
2000), el cual es realizado por el retinol y sus dos derivados: retinal y ácido retinoico. En los vegetales la vitamina A existe como una provitamina, el beta-caroteno. Debido a que no es metabolizado de manera eficaz a vitamina A, posee solo una sexta parte de eficiencia, comparado con el retinol, en cantidad equivalente (Mayes, 2000).

Tanto el déficit como el exceso de vitamina A provocan malformaciones congénitas graves que pueden afectar la cara, los ojos, el romboencéfalo, los miembros superiores y/o inferiores, el sistema urogenital, el diafragma y los pulmones (Carlson, 2014). Los retinoides se encuentran contraindicados en la gestación, y se solicitan tests de embarazo periódicos a pacientes que están utilizando este tratamiento para el acné, la psoriasis y otras anomalías dérmicas (Troncoso et al., 2008). Para la isotretinoína se ha determinado un alto potencial teratogénico, con un máximo riesgo durante el primer trimestre, persistente hasta 1 mes después de finalizado el tratamiento.

La administración oral diaria durante la gestación de $50 \mathrm{mg} / \mathrm{kg}$ de peso corporal de retinol, 10-27 mg/kg de ácido 13-cis retinoico ó 5, 10 ó $20 \mathrm{mg} / \mathrm{kg}$ de ácido all-trans retinoico, conduce a la formación de cantidades elevadas de potentes isómeros teratógenos. La presencia de grupos acídicos terminales en la molécula de ácido retinoico garantiza su unión a receptores nucleares, vía por la que es capaz de generar su efecto teratogénico (Hernández et al., 1998).

El retinol en la circulación materna se une a la Proteína Fijadora de Retinol (RBP), que es sintetizada por la placenta y entra en la circulación fetal. El ácido retinoico permanece en el citoplasma o entra en el núcleo de las células fetales, donde se une a los receptores nucleares del ácido retinoico. El complejo ácido retinoico-receptor actúa como un regulador de la transcripción de diversos genes moduladores (como la familia HOX) que tienen el apropiado elemento de respuesta a la vitamina A. En el caso de los genes $\mathrm{HOXb}$, su expresión interviene en el desarrollo cráneo-caudal con un orden $3^{\prime}-5^{\prime}$ (Ross et al.).

La expresión de las proteínas de unión y los receptores en diferentes tejidos y en diversos momentos de la embriogénesis puede ser un mecanismo de modulación selectiva a la acción del ácido retinoico (Maitra, 2010). Se dice que la dosis mínima para generar teratogenicidad en conejos es $15 \mathrm{mg} / \mathrm{kg} /$ día administrados entre los días 8 y 11 de la gestación, en hámsters de $37,5 \mathrm{mg} / \mathrm{kg} /$ día administrados entre los días 7 y 8 (Ekhoff \& Willhite, 1997), y en humanos $1 \mathrm{mg} / \mathrm{kg} /$ día (Troncoso et al.).

Existen muchos trabajos sobre las malformaciones que el ácido retinoico causaría en el Sistema Nervioso Cen- tral. El crecimiento fetal retardado y alteraciones cráneofaciales como la hipoplasia mandibular, microtia y anotia son las anomalías congénitas más informadas (Ross et al.; Pachajoa \& Ordóñez, 2012; Carlson), sin embargo la relación con cada segmento del sistema esquelético está menos estudiada. Este trabajo tiene como propósito describir los efectos que causa la administración de ácido retinoico a distintas dosis, sobre la morfogénesis ósea de cada segmento del esqueleto axial de embriones de ratón.

\section{MATERIAL Y MÉTODO}

Este trabajo se realizó atendiendo todas las normas éticas del trabajo con animales de bioterio, evitando causar dolor, angustia o miedo. Fue aprobado por el comité de ética de la Facultad de Medicina de la Universidad de Chile.

Se utilizaron 6 hembras vírgenes y 3 machos de 6 semanas de vida y entre 29 y 31 gramos de peso. Se introdujo un macho por jaula (cada jaula con dos hembras). Al día siguiente se revisó el tapón mucoso para constatar que hubo cópula. Las hembras que presentaron tapón mucoso se distribuyeron mediante aleatorización simple en 4 grupos (A, B, C y D). En el día 8 post fecundación al grupo A se le administró $40 \mathrm{mg} / \mathrm{kg}$ de peso de ácido trans retinoico (Sigma) disuelto en dimetil sulfóxido (DMSO). Al grupo B se administró $20 \mathrm{mg} / \mathrm{kg}$ de peso de ácido trans retinoico disuelto en DMSO. Al grupo C se inyectó $1 \mathrm{ml} / \mathrm{kg}$ de DMSO. Al grupo D control, no se administró solución. El día 17 de la gestación, todas las hembras y sus fetos fueron eutanasiados con una sobredosis de pentotal sódico inyectable intraperitoneal (180 mg/kg).

Previo a su estudio, los fetos fueron fijados en formalina al $10 \%$ en PBS y procesados mediante el método de Hanken \& Wassersug (Wassersug, 1976), según el cual fueron sometidos a digestión proteica (tripsina) y expuestos al colorante alizarina que tiñe de color rojo las sales de calcio presentes en los tejidos osificados y al colorante azul de Alcián, que tiñe azul el tejido cartilaginoso y los glicosaminoglicanos. Las muestras fueron visualizadas con lupa estereoscópica (Stemi DV4, Zeiss) y fotografiadas en formato digital (Canon A-640, 10 Megapixeles).

Los resultados se expresaron como porcentaje de malformaciones óseas en cada uno de los segmentos (cráneocervical, tóraco-abdominal y lumbar) considerándose un $100 \%$ cuando la totalidad de los elementos óseos se encontraban comprometidos. Se utilizó el test exacto de Fisher para la comparación de frecuencias de malformaciones y se consideró estadísticamente significativo cuando el p fue $<0,05$ 


\section{RESULTADOS}

La presencia de malformaciones según el grupo de tratamiento se resume en las Tablas I y II. Los grupos A y B (tratados con ácido retinoico) presentaron diferencias significativas con respecto a los grupos $\mathrm{C}$ (tratado con el vehículo DMSO) y D (control), los que no presentaron defectos anatómicamente visibles (Tabla I).

Tabla I. Presencia de malformaciones totales según grupo de tratamiento. Grupo A $(40 \mathrm{mg} / \mathrm{kg}$ de Ácido retinoico (AR); B (10 mg/Kg AR); C dimetil sulfóxido (DMSO); D sin tratamiento.

\begin{tabular}{lccc}
\hline Grupos & Si & No & Total \\
\hline A $(n=10)$ & 10 & 0 & $10^{*}$ \\
B $(n=6)$ & 6 & 0 & $6^{*}$ \\
C $(n=3)$ & 0 & 3 & 3 \\
D $(n=4)$ & 0 & 4 & 4 \\
\hline Se consideró un $p<0,05$ para la prueba exacta de Fisher * = vs. C \\
y D.
\end{tabular}

Todos los fetos de los grupos A presentaron defectos mayores o menores, y los del grupo B presentaron defectos menores en alguno de los segmentos óseos. En la Tabla II, se observa la distribución de malformaciones congénitas por segmento en ambos grupos. En el segmento cráneo-cervical, los huesos frontal parietal occipital fueron los más afectados (100\% de los fetos con el tratamiento A y $33,3 \%$ del grupo B). En el segmento tóraco-abdominal las costillas fueron las más afectadas en ambos grupos, apareciendo incluso algunas lumbares. Los fetos del grupo A presentaron alteraciones en los huesos de la cintura pélvica en un bajo porcentaje (20\%), y los del grupo B no presentaron ningún defecto en este segmento. Los fetos de los grupos C y D no presentaron malformaciones óseas.

En el grupo A, se observaron defectos mayores en el cráneo (Fig. 1a). La mandíbula, los huesos maxilares y nasales están osificados pero su morfología es anormal. Por ejemplo, la mandíbula no tiene curvatura. En el neurocráneo no se evidencia la osificación de los huesos frontal ni parietal, sin embargo, se observa el hueso occipital (supraoccipital, basioccipital y exoccipital) y también el atlas, aunque su tamaño es muy reducido(Fig. 1b). Dos fetos presentaron exencefalia y acrania, En otro caso se observó la presencia de una costilla cervical. En el segmento torácico se evidenciaron costillas fusionadas (T8-9 y T10-11) (Fig. 1c). Se observaron además costillas lumbares $(60 \%)$

En el grupo B, se observaron fetos con desarrollo de los huesos mandibular, maxilar y nasal. La osificación del hueso frontal es muy reducida, así como la osificación de los huesos parietales no se ha iniciado. Se observan los huesos occipitales (supraoccipital y basioccipital) prácticamente sin calcificación. Los arcos del atlas son apenas perceptibles. Los arcos vertebrales cervicales están calcificados, pero los cuerpos no presentan centros de osificación (Fig. 2a y $2 b)$. En un caso se evidenció una pequeña costilla cervical (Fig. 2b).

Tabla II. Malformaciones por segmento según dosis de AR. Se compararon grupos A y B.

\begin{tabular}{|c|c|c|c|c|c|c|}
\hline Segmento & Huesos & $A(n=10)$ & $\%$ & $B(n=6)$ & $\%$ & Valor de $p$ \\
\hline \multirow{8}{*}{ 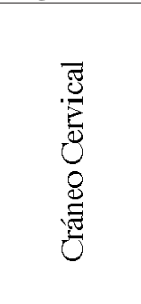 } & Frontal & $10^{*}$ & 100 & 2 & 33,3 & 0,008 \\
\hline & Parietal & $10 *$ & 100 & 2 & 33,3 & 0,008 \\
\hline & Temporal & $6^{*}$ & 60 & 0 & 0 & 0,034 \\
\hline & Occipital & $10 *$ & 100 & 3 & 50 & 0,036 \\
\hline & Nasal & 2 & 20 & 1 & 16,6 & 0,696 \\
\hline & Maxilar & 3 & 30 & 0 & 0 & 0,250 \\
\hline & Mandíbula & 4 & 40 & 0 & 0 & 0,234 \\
\hline & C. Cervical & 1 & 10 & 0 & 0 & 0,625 \\
\hline \multirow{6}{*}{ 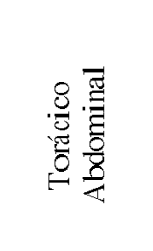 } & Escápula & 0 & 0 & 0 & 0 & $\mathrm{NC}$ \\
\hline & Clavícula & 0 & 0 & 0 & 0 & $\mathrm{NC}$ \\
\hline & C. Torácica & 9 & 90 & 6 & 100 & 0,625 \\
\hline & Costillas & 9 & 90 & 6 & 100 & 0,625 \\
\hline & C. Lumbar & 6 & 60 & 4 & 66,6 & 0,518 \\
\hline & C. Sacra & 0 & 0 & 0 & 0 & $\mathrm{NC}$ \\
\hline \multirow{3}{*}{ 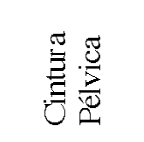 } & Ilion & 2 & 20 & 0 & 0 & 0,375 \\
\hline & Isquion & 2 & 20 & 0 & 0 & 0,375 \\
\hline & Pubis & 2 & 20 & 0 & 0 & 0,375 \\
\hline
\end{tabular}

$\mathrm{p}<0,05$ para la prueba exacta de Fisher *=vs. B. Grupo A= $40 \mathrm{mg} / \mathrm{kg}$ de Ácido retinoico. Grupo $\mathrm{B}=20$ $\mathrm{mg} / \mathrm{kg}$ Ácido retinoico. 

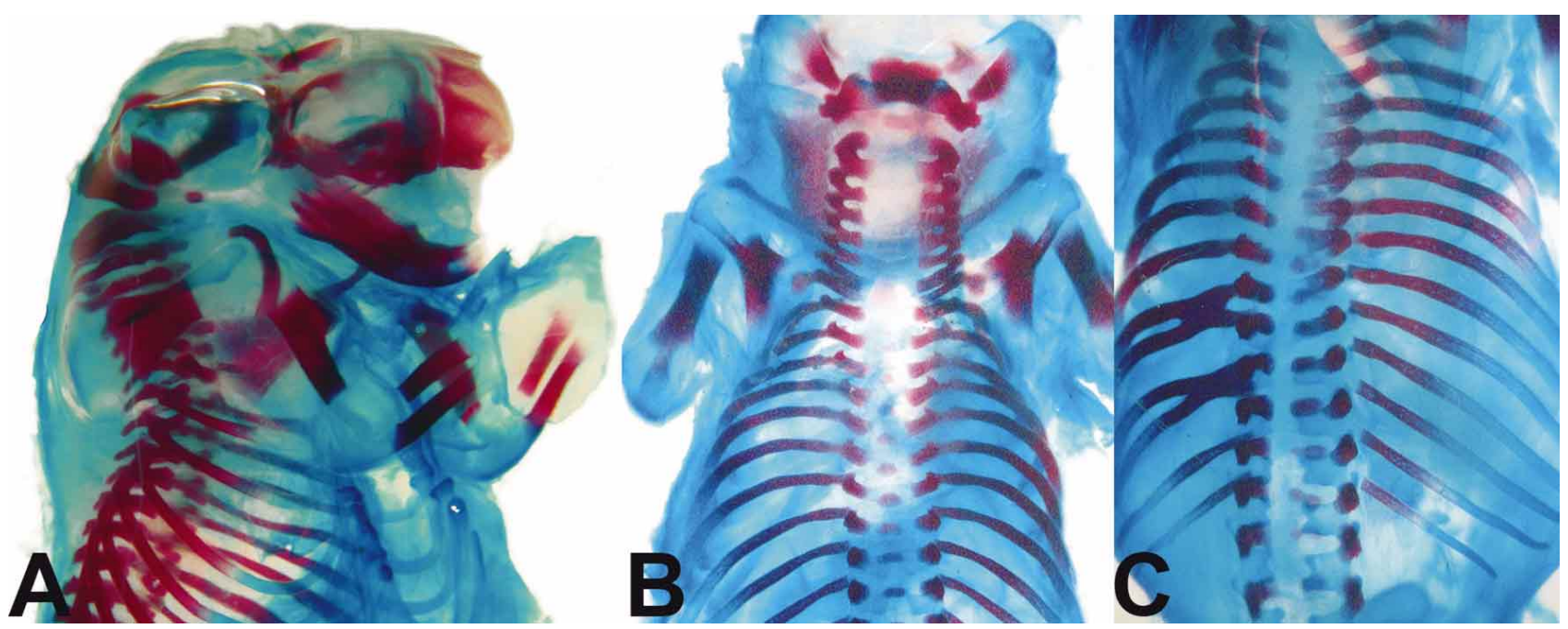

Fig. 1. A. Feto del grupo A, se caracteriza por la ausencia de huesos frontal y parietales. Se observa mandíbula sin curvatura y la presencia de hueso maxilar y nasal. B. Vista dorsal para observar occipital de tamaño reducido. C. Vista dorsal de tórax, se observan costillas parcialmente fusionadas muy próximas a la articulaciones costovertebrales izquierdas. Técnica de Haencken \& Wassersug.
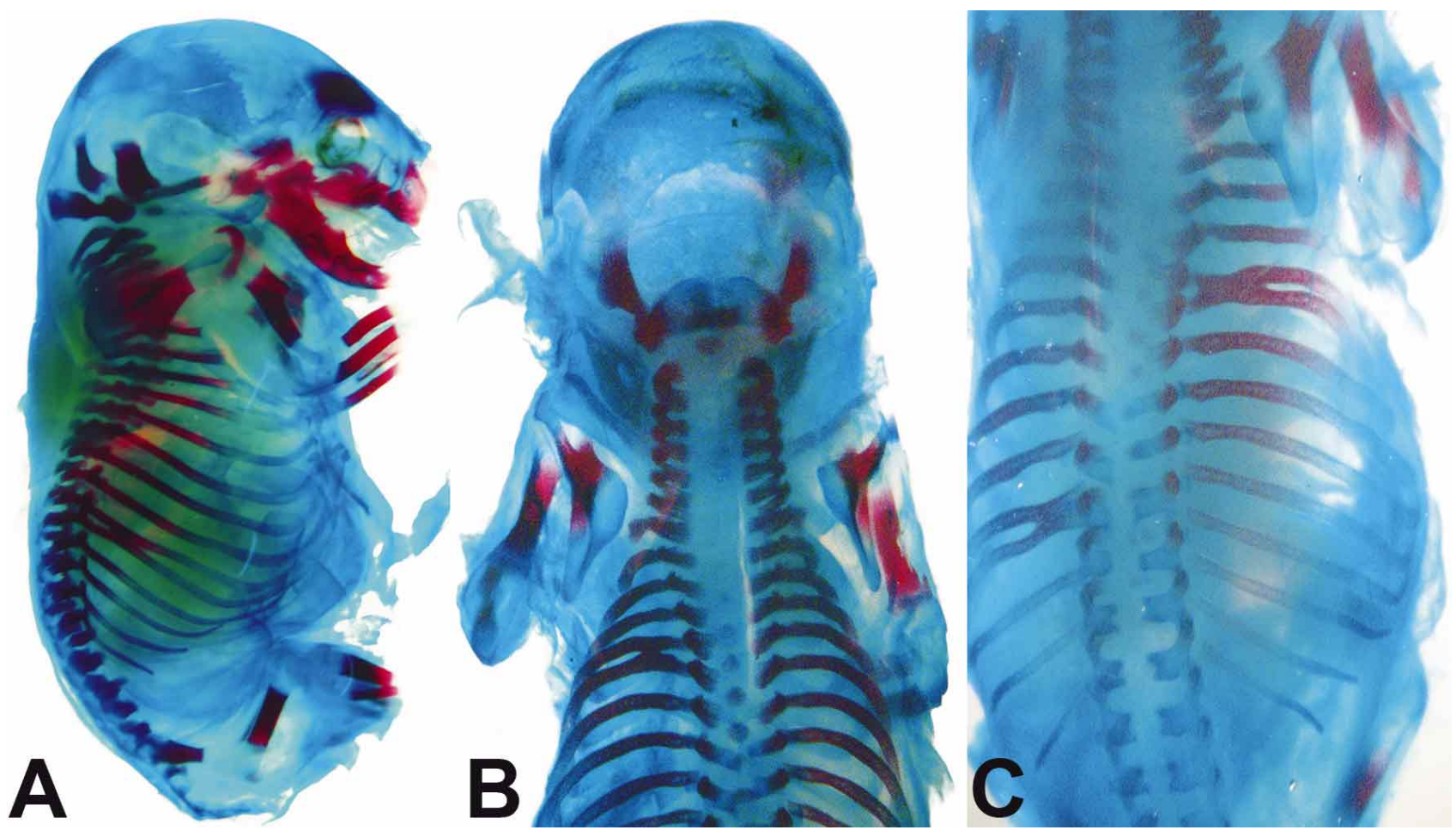

Fig. 2. A. Vista lateral de feto del grupo C. La osificación del hueso frontal es reducida, la mandíbula y hueso maxilar son normales, No se observa parietal ni interparietal osificado, el occipital (O) (que está formado por supra occipital, basioccipital y exo-occipital) tiene tamaño reducido. B. Vista dorsal de feto del mismo grupo. En el segmento torácico se observa que dos costillas del lado izquierdo están fusionadas. C. Vista dorsal de otro feto del mismo grupo. Se observan dos pares de costillas fusionadas parcialmente al lado izquierdo y uno al lado derecho. Técnica de Haencken \& Wassersug. 
En relación al segmento tóraco-abdominal que considera los huesos: escápula, clavícula, columna torácica, costillas, columna lumbar y sacra, no se encontraron malformaciones mayores anatómicamente notables, pero sí se evidenciaron costillas supernumerarias, cortas cartilaginosas y con fusiones costales (Figs. 2b y 2c) que podían afectar el lado derecho, el lado izquierdo o ambos. Además se observaron costillas lumbares $(66,6 \%)$.

En el grupo C, no se encontraron defectos en la forma de los huesos. La mandíbula, premaxilar, maxilar y nasal resultaron morfológicamente normales, sin embargo el avance de la progresión de la osificación fue más limitado que en los controles. Los huesos occipitales fueron normales.

En el grupo D (control) se observó lo siguiente: El viscerocráneo está constituido por dos huesos mandibulares que se unen en la región distal de la sínfisis. El cuerpo de la mandíbula se ha osificado y calcificado. Es posible reconocer los huesos: premaxilar, maxilar y nasal (Figs. 4a).

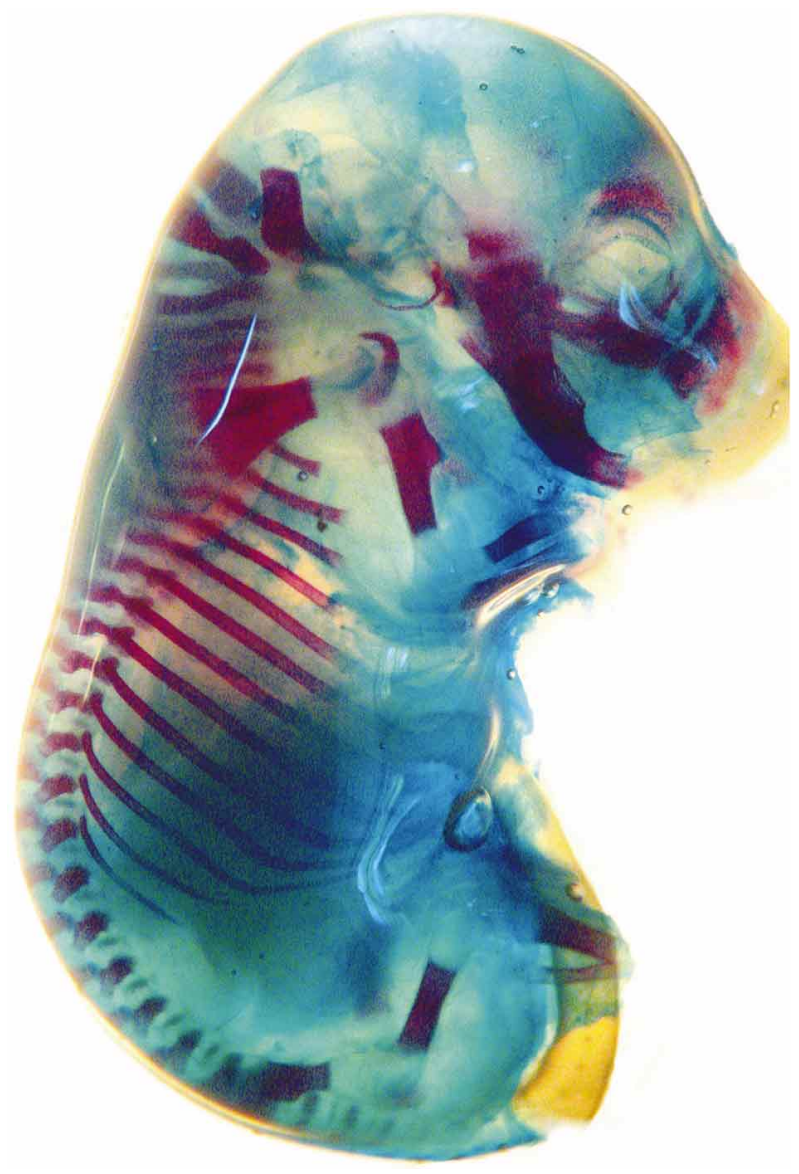

Fig. 3. Vista lateral de feto de grupo C. Mandíbula, maxilar y hueso nasal bien osificados Hueso frontal con retardo de osificación. Occipital y Atlas normal. Esqueletos apendicular y axial normales Técnica de Haencken \& Wassersug.
En el neurocráneo se observa la formación del hueso frontal con una tinción intensa debido a la alizarina y los huesos parietales (e interparietal) aparecen débilmente teñidos pero se puede reconocer las espículas óseas en formación (Fig. 4a). Además, se puede ver los huesos occipitales (supra occipital, exoccipital, basioccipital), como también el arco anterior y posterior del atlas y las siete vértebras cervicales que no presentan centros de osificación (Fig. 4b). En el segmento tóraco- abdominal se encuentra una clavícula grande articulada $(2 \mathrm{~mm})$ fácilmente identificable. En la escápula se observa progresión de la osificación endocondral, no obstante, la región más proximal permanece cartilaginosa. Se identifican 13 costillas unidas a las vértebras torácicas, siete de ellas se unen al esternón y seis quedan flotantes y no se unen a éste (Fig. 4c), el que permanece aún completamente cartilaginoso. La columna vertebral presenta puntos de osificación en la región torácica, que disminuyen en extensión a medida que nos acercamos al segmento lumbar. Respecto de la cintura pélvica, se puede reconocer el ílium fácilmente debido a que se encuentra en osificación, mientras que el ísquium y pubis no lo están aún (Fig. 4d). Los puntos de osificación de las vértebras se extienden hasta la zona lumbar.

\section{DISCUSIÓN}

Se encontraron diferencias estadísticamente significativas entre ambos grupos de embriones tratados con ácido retinoico y los grupos tratados con el vehículo (DMSO) y el grupo control $(\mathrm{p}<0,05)$. También se encontraron diferencias significativas entre los grupos tratados con distintas concentraciones de ácido retinoico. El ácido retinoico es un potente morfógeno sintetizado y secretado por los somitos, que participa en el establecimiento del patrón céfalo caudal del embrión mediante la activación de la expresión de genes específicos de una manera dependiente de la concentración (Gurdon \& Bourillot; Rojas \& Smok, Olivares \& Rojas, 2013; Rojas et al.). Los cambios en las gradientes de ácido retinoico pueden alterar el orden de la expresión de genes HOX y producir malformaciones congénitas en el desarrollo del esqueleto axial y apendicular (Rojas et al.). La sobreexpresión de un gen HOX da como resultado defectos localizados en las partes anteriores de las regiones en las que el gen es expresado, y puede causar transformaciones homeóticas (Kessel \& Gruss, 1991; Carapuco et al., 2005; Rojas et al.).

En relación al segmento cráneo-cervical, las malformaciones mayores correspondieron a exencefalia, ausencia de huesos frontales y parietales y mandíbula deformada, estando significativamente más afectados los fetos del grupo A, 

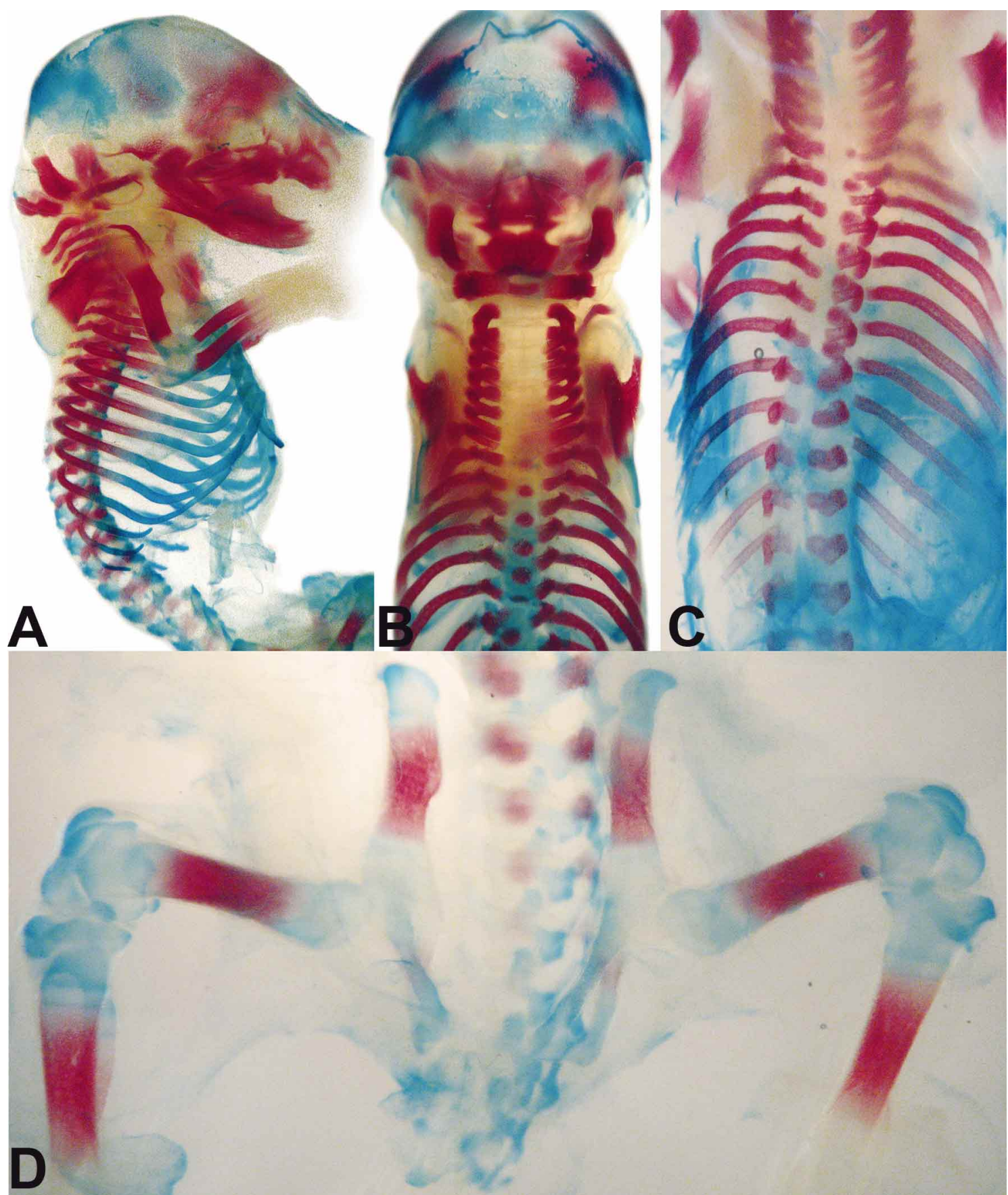

Figura 4. A. Vista lateral derecha de feto de grupo control. La mandíbula, maxila, hueso nasal, hueso frontal y occipital osificados. Vértebras cervicales, clavícula y huesos del esqueleto axial bien osificados. B. Vista dorsal de feto del grupo control Se observa occipital (basioccipital, supraoccipital, exooccipital y atlas), vértebras cervicales y torácicas. C. Segmento torácico con costillas osificadas. D. Feto del grupo D. Se observa osificación membranosa en el ilion, mientras que isquion y pubis están en fase membranosa a cartilaginosa. Técnica de Haencken \& Wassersug.

tratados con $40 \mathrm{mg} / \mathrm{kg}$ de ácido retinoico, en comparación con el grupo B, tratados con $20 \mathrm{mg} / \mathrm{kg}$ de ácido retinoico. Esto es similar a lo encontrado por González et al. (2003), quienes suministraron el día 10 y por vía oral una dosis mayor a la del presente estudio (125 $\mathrm{mg} / \mathrm{kg}$ de peso), a ratas preñadas
Sprague-Dawley, obteniendo resultados como exencefalia, huesos faciales de menor tamaño y fisuras faciales. Estos autores relacionan las malformaciones descritas con errores en la migración de las células de la cresta neural craneal a los primordios faciales en desarrollo. 
Según nuestro estudio, tanto la parte membranosa del cráneo (frontal, nasal, escama del temporal, maxilar, mandibular), derivada de las células de la cresta neural, como también los huesos derivados del mesodermo lateral somático (parietal, petroso temporal y occipital) resultaron afectados por el ácido retinoico exógeno. Se debe destacar que los genes HOX no participan en la identidad regional de los huesos del cráneo a diferencia de los siguientes segmentos. Según Meruane et al. (2012), los precursores del primer arco faríngeo que forma gran parte de la cara no se expresan por los genes HOX. Por otra parte, en relación a la columna cervical nosotros observamos una vértebra cervical con costillas, lo que indica una transformación homeótica de una vértebra cervical en una torácica.

Respecto del segmento tóraco-abdominal, la columna vertebral y las costillas en los cordados se forman desde el esclerotoma, un tejido mesenquimático poco diferenciado constituido por células mesenquimales y matriz extracelular, que está ubicado en la porción ventromedial de cada somito a ambos lados del tubo neural. Sus células migran para rodear la notocorda (Olivares \& Rojas). Existen somitos occipitales, cervicales, torácicos lumbares y sacros (Rojas et al.). Kessel \& Gruss reportaron como normal en el ratón 36 vértebras distribuidas en 7 cervicales, 13 torácicas, 6 lumbares, 4 sacras y 6 caudales. El establecimiento ordenado de las vértebras (cervicales, torácicas, lumbares, sacras y caudales), depende de la expresión de los genes HOX, quienes especifican la identidad posicional a lo largo del eje anteroposterior (Wolpert, 2009). Nosotros encontramos costillas supernumerarias y transformación de vértebras lumbares en torácicas, lo cual concuerda con estudios de Kessel \& Gruss y Kessel (1992) quienes comprobaron que en embriones expuestos a ácido retinoico el día 8 de la gestación, la primera o segunda vértebra lumbar se transformaba en torácica, mientras que la primera vértebra sacra usualmente se convertía en lumbar. De esta manera, la expresión del gen HOX 10 fue desplazada hacia posterior, agregándose un set adicional de costillas en lo que corresponde a la primera vértebra lumbar (Gilbert, 2013). En nuestro estudio reportamos costillas fusionadas uni o bilaterales, lo cual no fue informado por Kessel \& Gruss.

En relación al grupo C tratado con DMSO no observamos malformaciones congénitas. Se ha reportado al DMSO como teratogénico a dosis extremadamente altas, razón por la cual se decidió incluir un grupo control interno, al que se administró únicamente este vehículo a dosis 2500 veces menor a las teratogénicas reportadas. Los resultados encontrados permiten descartar la influencia del excipiente en las anomalías descritas, y avalar las instrucciones que plantean que este vehículo a dosis bajas no generaría daño (Ferm, 1966) pues todos los fetos presentaban huesos anatómicamente normales.

\section{CONCLUSIONES}

El ácido retinoico (en su isómero isotretinoína) administrado a los 8 ds p.f en dosis de 40 y $20 \mathrm{mg} / \mathrm{kg}$ de peso actúa como un teratógeno en los embriones de ratón. Hay diferencias significativas entre los defectos inducidos por concentraciones de $40 \mathrm{mg} / \mathrm{kg}$ y $20 \mathrm{mg} / \mathrm{kg}$ de ácido retinoico. La primera concentración afecta los huesos de los tres segmentos estudiados (cráneo-cervical, tóraco-abdominal, y pélvico) y la segunda concentración sólo afecta a dos segmentos. (cráneo-cervical y tóraco abdominal) en una gradiente céfalo caudal independiente del origen embrionario de cada hueso. Los cambios en las gradientes de ácido retinoico alteran el orden de la expresión de genes HOX. Al aumentar la concentración en el gradiente, las células captarán una concentración de morfógeno elevada, cambiarán su respuesta a un nivel más alto y se generarán así malformaciones congénitas. De acuerdo a esto, existe una relación directa entre la concentración de ácido retinoico exógeno y el porcentaje de huesos malformados por segmento, y se presenta entonces una gradiente de defectos que no depende del origen embrionario (p.ej ectomesénquima ó mesodermo somítico) sino más bien de la ubicación a lo largo del eje céfalocaudal.

OJEDA, M. G.; LOPEZ, T. Y.; DIAZ, N. M. \& ROJAS, R. M. Effect of administration of retinoic acid on the development of the axial skeleton in mouse embryos Mus musculus. Int. J. Morphol., 32(4):1449-1456, 2014.

SUMMARY: The deficit and excess of vitamin A causes birth defects affecting different organ systems. The objectives of this study are to determine the effect caused by the administration of different doses of retinoic acid on bone morphogenesis of the axial skeleton in embryonic mouse Mus musculus. By simple randomization newly pregnant females were distributed into 4 categories: A, B, C and D. On day 8 post fertilization, $40 \mathrm{mg} / \mathrm{kg}$ was administered by weight of retinoic acid to the group A, $20 \mathrm{mg} / \mathrm{kg}$ body weight of the group B solution $1 \mathrm{ml} / \mathrm{kg}$ body weight of dimethyl sulfoxide and group C. Group $\mathrm{D}$ is the control group. On day 17 of gestation the females and their fetuses were anesthetized and euthanized with an overdose of intraperitoneal sodium pentothal. Fetuses from each litter were processed using diaphanization and Alcian blue staining to hyaline cartilage and alizarin to observe bone tissue. The results are expressed as percentages of malformations in the following three segments: 1) cranio-cervical spine, 2) thoracic and abdominal segment and 3) pelvic segment, considering $100 \%$ when all the bony elements were compromised. Fisher's exact test for comparison of frequencies of malformations was used and considered statistically significant when $\mathrm{p}<0.05$. In group $\mathrm{A}$, major malformations and defects were evident in the indemnity of the cranial vault, exencephaly, defects in the number of vertebrae, and fusion of ribs. In group B minor malformations as numerical alterations and rib fusions were observed. Significant differences were found between both groups. In groups C and D no malformations were recorded. Retinoic acid administered 
intraperitoneally at doses of 40 and $20 \mathrm{mg} / \mathrm{kg}$ acts as a teratogen in mouse embryos. There are significant differences between the defects induced by concentrations of $40 \mathrm{mg} / \mathrm{k}$ and $20 \mathrm{mg} / \mathrm{k}$ of retinoic acid. Both concentrations affect the bones of the three segments studied (cranio cervical, thoraco-abdominal and pelvic) in a cephalo caudal gradient, independent of the embryonic origin of the structures. Changes in retinoic acid concentration alter the behavior of cranial neural crest and changing the order of the HOX gene expression in the axial skeleton.

KEY WORDS: Retinoic acid; Axial skeleton; Congenital malformations; Mus musculus; Fetus; Mouse.

\section{REFERENCIAS BIBLIOGRÁFICAS}

Brito, M. F. M.; Pessoa, I. S.; Galindo, J. C. S.; Rosendo, L. H. P. M. \& Santos, J. B. Avaliação dos efeitos adversos clínicos e alterações laboratoriais em pacientes com acne vulgar tratados com isotretinoína oral. An. Bras. Dermatol., 85(3):331-7, 2010.

Carapuco, M.; Nóvoa, A.; Bobola, N. \& Mallo, M. Hox genes specify vertebral types in the presomitic mesoderm. Genes Dev., 19(18):2116-21, 2005.

Carlson, B. Embriología Humana y Biología del Desarrollo. $5^{\text {a }}$ ed. Barcelano, Elsevier, 2014.

Crandall, J.; Sakai, Y.; Zhang, J.; Koul, O.; Mineur, Y.; Crusio, W. E. \& McCaffery, P. 13-cis-retinoic acid suppresses hippocampal cell division and hippocampal-dependent learning in mice. Proc. Natl. Acad. Sci., 101(14):5111-6, 2004

Ekhoff, C \& Willhite, C. Embryonic Delivered Dose of Isotretinoin (13-cis-Retinoic Acid) and its Metabolites in Hamsters. Toxicol. Appl. Pharmacol., 146(1):79-87, 1997.

Ferm, V. H. Congenital malformations induced by dimethyl sulphoxide in the golden hamsters. Embryol. Exp. Morph., 16(1):49-54, 1966.

González, T.; Lassaletta, L.; Martínez, L.; Tovar, J \& Martorell, V. Estudio morfométrico de las malformaciones cráneofaciales experimentales inducidas por ácido retinoico. Rev. Esp. Cirug. Oral y Maxilofac., 25(5):288-93, 2003

Gilbert, S. F. Developmental Biology. $10^{\text {th }}$ Ed. Sunderland, Sinauer Associates Inc., 2013.

Gurdon, J. B. \& Bourillot, P. Y. Morphogen gradient interpretation. Nature, 413(6858):797-803, 2001.

Hernández, M.; Porrata, C \& Jiménez, S. Toxicidad de la vitamina A durante el embarazo. Rev. Méd. Cubana, 11(3):153-8, 1998.

Kessel, M. \& Gruss, P. Homeotic transformations of murine vertebrae and concomitant alteration of Hox codes induced by retinoic acid. Cell, 67(1):89-104, 1991.

Kessel, M. Respecification of vertebral identities by retinoic acid. Development, 115(2):487-501, 1992.
Maitra, A. Enfermedades de la lactancia y de la infancia. En: Kumar, V.; Abbas, A. K.; Fausto, N. \& Aster, J. (Eds.). Robbins y Cotran. Patología estructural y funcional. 8a Ed. Elsevier, Barcelona, 2010.

Mayes, P. Estructura y función de las vitaminas liposolubles. Bioquímica. $15^{\text {a }}$ ed. El Manual Moderno, México, 2000.

Meruane, M.; Smok, C. \& Rojas, M. Face and Neck Development in Vertebrates. Int. J. Morphol., 30(4):1373-88, 2012.

Olivares, R. \& Rojas, M. Axial and Appendicular Skeleton of Vertebrates. Int. J. Morphol., 32(2):378-87, 2013.

Pachajoa, H. \& Ordóñez, A. Embriopatía por isotretinoína con microtiaanotia y cardiopatía. Presentación de un caso. Arch. Argent. Pediatr., 110(3):e47-9, 2012.

Rojas, M. \& Walker, L. Congenital Malformations: General and Genetic Aspects. Int. J. Morphol., 30(4):1256-1265, 2012.

Rojas, M.; Signore, I. A. \& Mejías, R. Morphogens During Embryonic Development of Vertebrates. Int. J. Morphol., 32(1):319-26, 2014.

Rojas, M. \& Smok, C. Modelando el cuerpo durante el período somítico. Int. J. Med. Surg. Sci., 1(1):57-62, 2014.

Ross, S.; Mac Caffery, P.; Drager, U. \& De Luca, L. Retinoids in embryonal development. Physiol. Rev., 80(4):1021-54, 2000.

Tabata, T. \& Takei, Y. Morphogens, their identification and regulation. Development, 131(4):703-12, 2004.

Troncoso, M.; Rojas, C. \& Bravo, E. Embriopatía por isotretinoína: Un daño evitable. Rev. Med. Chile, 136(6):763-6, 2008.

Wassersug, R. J. A procedure for differential staining of cartilage and bone in whole formalin fixed vertebrates. Stain. Technol., 51:1314, 1976.

Wolpert, L. Principios del Desarrollo. $3^{\mathrm{a}}$ ed. Madrid, Médica Panamericana, 2009.

Dirección para Correspondencia:

Dra. Mariana Rojas R.

Laboratorio de Embriología Comparada

Programa de Anatomía y Biología del Desarrollo

Facultad de Medicina, ICBM

Universidad de Chile

Santiago - CHILE

Email: dramrojas@hotmail.com

Prof. Asist. Marcela Díaz Navarrete

Departamento de Promoción de la Salud de la Mujer y el Recién Nacido, Facultad de Medicina

Universidad de Chile

Santiago - CHILE

Email: mdiaz@med.uchile.cl_ Recibido : 16-09-2014

Aceptado: 11-10-2014 